\title{
Effect of Compaction Moisture Content on the Resilient Modulus of Unbound Aggregates from Senegal (West Africa)
}

\author{
Makhaly Ba, Meissa Fall, Oustasse Abdoulaye Sall, Fatou Samb \\ Laboratoire de Mécanique et Modélisation (L2M), UFR Sciences de l'Ingénieur, University of Thies, Thies, Senegal \\ Email: makhaly.ba@univ-thies.sn
}

Received October 22, 2011; revised November 29, 2011; accepted December 22, 2011

\begin{abstract}
This paper presents the results of research conducted to investigate the effect of compaction moisture content on Resilient Modulus $\left(M_{r}\right)$ of unbound aggregates. Three different aggregates (GRB, Basalt and Bandia limestone) was collected from different sites within Senegal and then subjected to repeated load triaxial tests. Test results showed that the effect of compaction water content is more significant in the dry side than in the wet side. The compaction water content has less effect on the GRB and the Basalt than on the Bandia limestone. GRB and Basalt are cohesionless materials and allow water to drain even during the compaction procedure. Change in water content increases as the compaction water content increases because of the drainage of the excess water during the compaction and loading procedures. For GRB and Basalt, at $\mathrm{W}_{\text {opt }}+1.5 \%$, most of the excess water is drained during the compaction of the sample and continue to be drained during the Resilient Modulus test. For the Bandia limestone, this drainage is less significant due to cohesion, absorption and hydratation.
\end{abstract}

Keywords: Resilient Modulus; Summary Resilient Modulus; Quartzite; Basalt; Bandia Limestone

\section{Introduction}

Proper characterization of the mechanical response of unbound aggregate materials is a key element in the design and rehabilitation of pavement structures [1]. The Resilient Modulus $\left(M_{r}\right)$ is used as the mechanical property to describe stress-stain relationship of unbound material under cyclic loading and given physical conditions. Resilient modulus $\left(M_{r}\right)$ represents the elastic modulus that account for the non linear behavior of unbound base and subbase courses.

Under given confining pressure, the Resilient Modulus is defined as the slope of the deviator stress-axial strain curve (Figure 1) [2], or the ratio between the deviator stress $\left(\sigma_{d}\right)$ and the recoverable axial strain $\left(\varepsilon_{1, r}\right)$ (Equation (1)).

$$
M_{r}=\frac{\left(\sigma_{1}-\sigma_{3}\right)}{\varepsilon_{1, r}}=\frac{\sigma_{d}}{\varepsilon_{1, r}}
$$

where $M_{r}$ is the Resilient Modulus, $\sigma_{1}$ is the major principal stress, $\sigma_{3}$ is the minor principal stress and $\sigma_{d}$ is the deviatoric stress $\left(\sigma_{1}-\sigma_{3}\right)$.

Many constitutive equations have been developed to model the resilient behavior of unbound base and subbase courses [3]. A bulk stress of $\theta=208 \mathrm{kPa}$ is used in this study to calculate a Summary Resilient Modulus acc- ording to the Seed et al. model [4] (Equation (2)):

$$
M_{r}=k_{1}\left(\frac{\theta}{P_{a}}\right)^{k_{2}}
$$

$\theta=\sigma_{1}+2 \sigma_{3}$ is the bulk stress; $k_{1}$ and $k_{2}$ are the material properties and $P_{a}$ is the atmospheric pressure (100 $\mathrm{kPa})$.

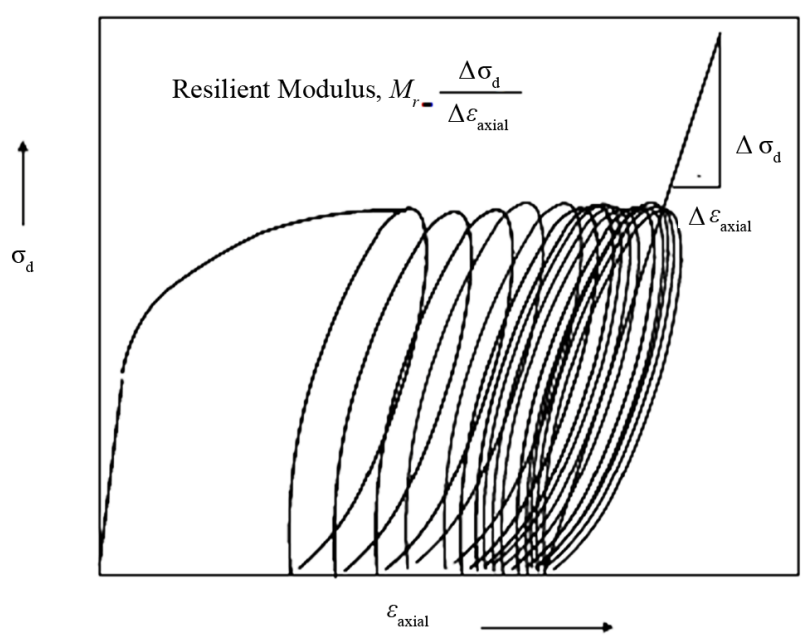

Figure 1. Definition of resilient modulus [2]. 
Resilient Modulus of unbound granular materials is affected by several parameters, some of which are stress level and moisture content [5]. Apart from stress level, the compaction moisture content appears to be the most important factor affecting Resilient Modulus of unbound base courses. Generally, the Resilient Modulus decreases as water content increases. But the rate of decreasing depends on the aggregate type and the grain size distribution.

Several researches were conducted to investigate the Resilient Modulus of unbound aggregate base courses from Senegal [6,7]. The effect of density and the input parameters for Mechanistic-Empirical flexible pavement design were determined on four different aggregates: Red quartzite and Black quartzite from Bakel, Basalt from Diack and Limestone from Bandia. Result show that the Bandia limestone is stiffer than the basalt but the basalt is stiffer than the Red and the Black quartzites. The Bandia limestone is more sensitive to water content than the quartzites. This paper presents the effect of water content before compaction and after compaction and Resilient Modulus test to understand the changes in water content during the Resilient Modulus test procedure.

\section{Material Properties and Testing Procedure}

\subsection{Materials}

Three different aggregate base or subbase courses were subjected to Resilient Modulus tests: Red quartzite from Bakel (GRB), Basalt from Diack (BAS), and Limestone from Bandia (BAN). Particle size distributions of the materials tested were conducted according to ASTM C136-06 [8]. Modified compaction test was conducted according to ASTM D1557-09 [9]. Specific gravity and Micro-Deval losses were determined according to C12707 [10] and ASTM D6928-10 [11], respectively. Figure 2 and Table 1 present particle size distributions and physical properties taken from $\mathrm{Ba}$ et al. [7]. Repeated load triaxial test was used to determine the Resilient Modulus of these aggregates. The three different materials were compacted at $98 \%$ of the maximum dry unit weight for the GRB and the basalt, and 95\% of the maximum dry unit weight for the Bandia limestone [7].

\subsection{Resilient Modulus Test Procedure}

Specimens with 6 inches diameter and 12 inches height were subjected to the Resilient Modulus test procedure. A MTS closed-loop servo-electro-hydraulic testing system was used to apply the cyclic loading in a haversine waveform, with 0.1 second of loading duration and 0.9 second of rest period. Displacements were measured internally using "Linear Variable Displacement Transducer"

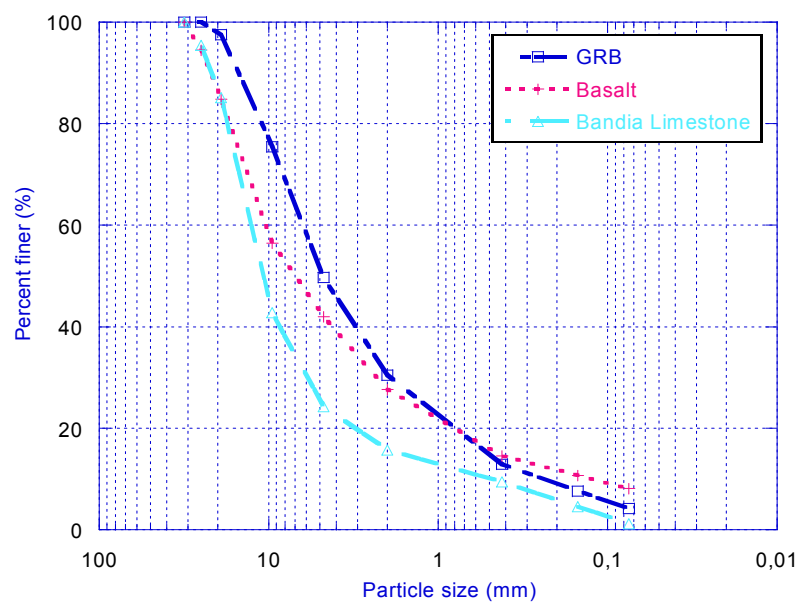

Figure 2. Grain size distribution of GRB, BAS and BAN [7].

Table 1. Some physical and mechanical material properties [7, modified].

\begin{tabular}{ccccc}
\hline Materials & $\boldsymbol{\rho}_{\text {dmax }}\left(\mathbf{k g} / \mathbf{m}^{\mathbf{3}}\right)$ & $\mathbf{W}_{\text {opt }}(\mathbf{\%})$ & $\mathbf{G}_{\mathbf{s}}$ & MDE (\%) \\
\hline GRB & 2140 & 5.5 & 2.65 & 3.07 \\
BAS & 2420 & 4.2 & 2.95 & 5.66 \\
BAN & 2065 & 7.6 & 2.56 & 40.0 \\
\hline
\end{tabular}

("LVDT") mounted around the specimen inside the cell. The specimens have been tested using the NCHRP Protocol 1-28A [12]. Each specimen was conditioned with $103.5 \mathrm{kPa}$ confining pressure, and 1000 cycles of 207 $\mathrm{kPa}$ deviator stress. The cycles are repeated 100 times for 30 loading sequences with different combinations of confining pressures and deviator stresses. The last five cycles of each sequence are used to calculate the Resilient Modulus.

\section{Resilient Modulus Results and Analyses}

Figures 3-5 present the effect of compaction water content on the Resilient Moduli of GRB, Basalt and Bandia limestone, respectively. Each sample has been compacted at three different moisture content $\left(\mathrm{W}_{\mathrm{opt}}, \mathrm{W}_{\mathrm{opt}}-2\right.$ and $\mathrm{W}_{\mathrm{opt}}+1.5$ ). The spread in the data at a constant confining pressure represents the $M_{r}$ at various deviator stresses. The curve fit is based on power dependence on confinement. These figures show that the Resilient Modulus of GRB increases about $10 \%$ and $24 \%$ when water content decreases respectively from $\mathrm{W}_{\text {opt }}$ to $\mathrm{W}_{\text {opt }}-2$ and from $\mathrm{W}_{\text {opt }}+1.5$ to $\mathrm{W}_{\text {opt }}-2$. For the Basalt, Resilient Modulus increases about $32 \%$ and $40 \%$ when water content decreases respectively from $\mathrm{W}_{\text {opt }}$ to $\mathrm{W}_{\text {opt }}-2$ and from $\mathrm{W}_{\text {opt }}+1.5$ to $\mathrm{W}_{\text {opt }}-2$. Resilient Modulus of Bandia limestone increases about $59 \%$ and $87 \%$ when water content decreases respectively from $\mathrm{W}_{\text {opt }}$ to $\mathrm{W}_{\text {opt }}-2$ and from $\mathrm{W}_{\mathrm{opt}}+1.5$ to $\mathrm{W}_{\mathrm{opt}}-2$. Then the Bandia limestone is much more sensitive to water content than the GRB and the Basalt. 


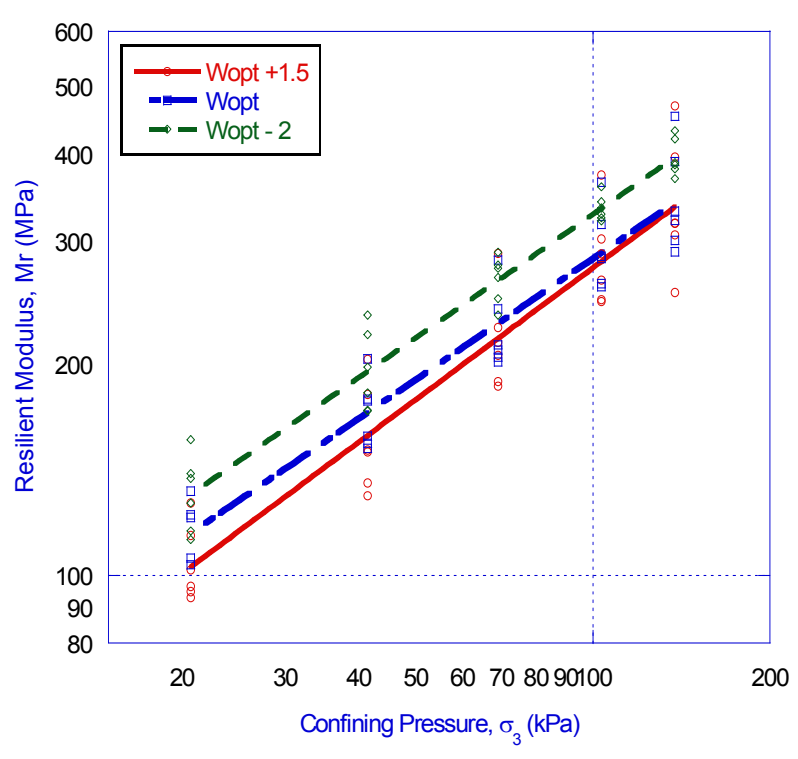

Figure 3. $M_{r}$ vs confining pressure for GRB tested at three different water contents.

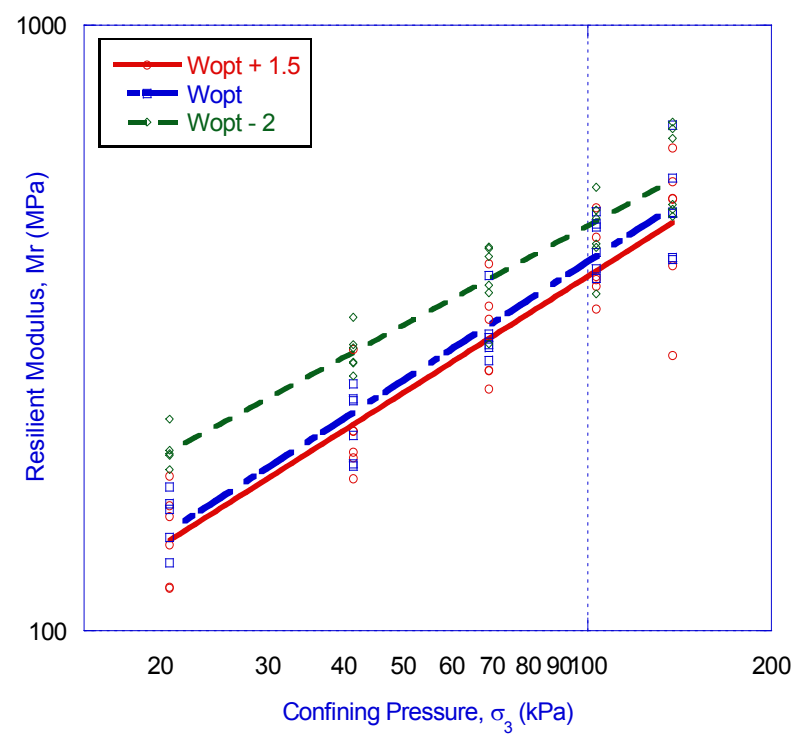

Figure 4. $M_{r}$ vs confining pressure for Basalt tested at three different water contents.

Figures 6-8 show the variation of the Summary Resilient Moduli (SRM) with water content before compaction and after compaction and Resilient Modulus test for the three materials tested. Each material has been tested for three compaction water content $\left(\mathrm{W}_{\mathrm{opt}}-2 \%, \mathrm{~W}_{\mathrm{opt}}\right.$ and $\mathrm{W}_{\text {opt }}+1.5 \%$ ). The SRM of GRB increases about $20 \%$ when the compaction water content decreases from $\mathrm{W}_{\text {opt }}$ to $\mathrm{W}_{\text {opt }}-2 \%$ and decreases only about $11 \%$ when water content increases from $\mathrm{W}_{\mathrm{opt}}$ to $\mathrm{W}_{\mathrm{opt}}+1.5 \%$. For the Basalt, the SRM of GRB increases about $29 \%$ when water content decreases from $\mathrm{W}_{\mathrm{opt}}$ to $\mathrm{W}_{\mathrm{opt}}-2 \%$ and decreases about $10 \%$ when water content increases from $\mathrm{W}_{\text {opt }}$ to

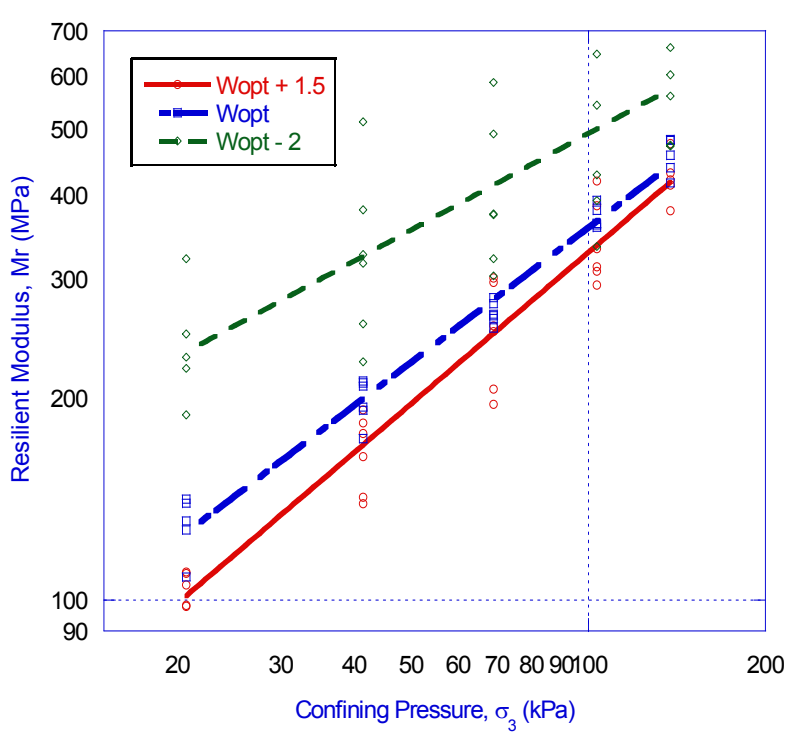

Figure 5. $M_{r}$ vs confining pressure for Bandia limestone tested at three different water contents.

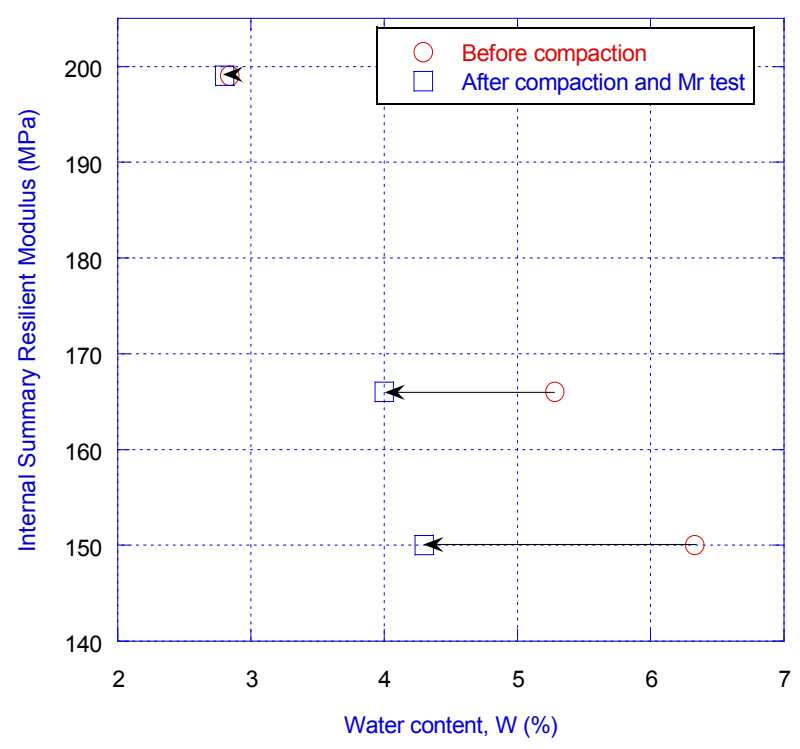

Figure 6. Internal SRM vs Water content before compaction and after compaction and $M_{r}$ test (GRB).

$\mathrm{W}_{\text {opt }}+1.5 \%$. The SRM of Bandia limestone in creases about $81 \%$ when the water content decreases from $\mathrm{W}_{\text {opt }}$ to $\mathrm{W}_{\mathrm{opt}}-2 \%$ and decreases about $25 \%$ when the water content increases from $\mathrm{W}_{\text {opt }}$ to $\mathrm{W}_{\text {opt }}+1.5 \%$. These results show that the effect of water content is more significant in the dry side than in the wet side. The compaction water content has less effect on the GRB and the Basalt than on the limestone. GRB and Basalt are co-hesionless materials and allow water to drain even during the compaction procedure as shown by the change in water content of these materials before compaction and after compaction and Resilient Modulus test. 
Figure 9 shows the change in water content before compaction and after compaction and Resilient Modulus test. This change is much more important in the GRB and the Basalt than in the Bandia limestone. Change in water content before compaction and after compaction and $M_{r}$ test increases as the compaction water content increases due to drainage of the excess water during the compaction procedure. For GRB and Basalt, at $\mathrm{W}_{\mathrm{opt}}+1.5 \%$, most of the excess water is drained during the compaction of the sample and continue to be drained during the Resilient Modulus test. For the Bandia limestone, this drainage is less significant due to cohesion, absorption and hydratation.

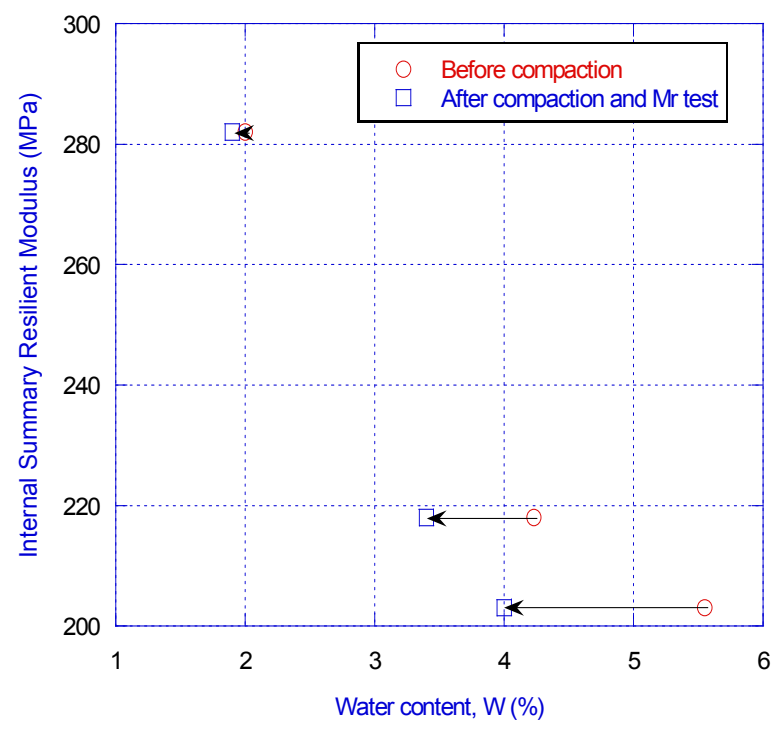

Figure 7. Internal SRM vs Water content before compaction and after compaction and $M_{r}$ test (Basalt).

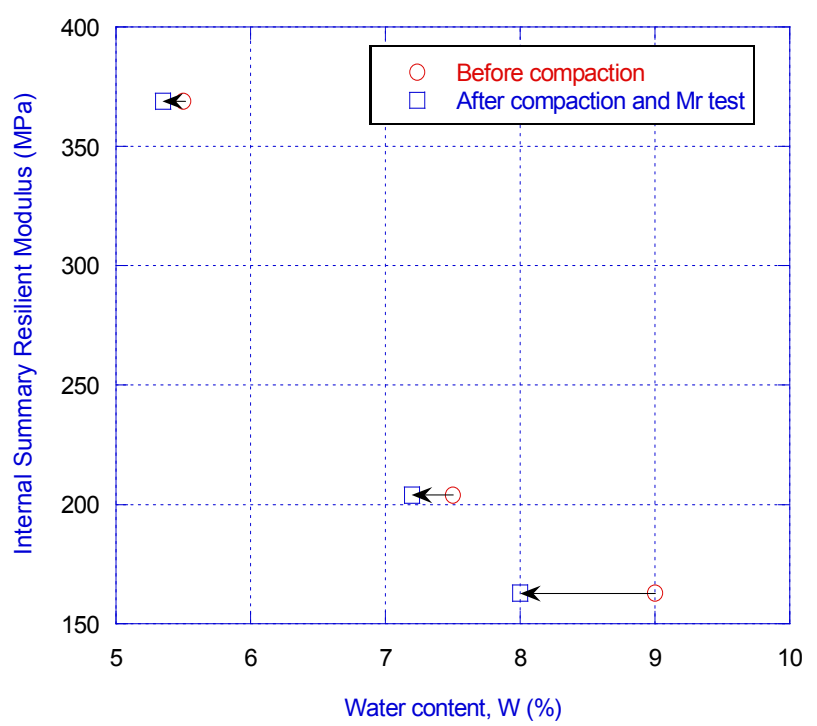

Figure 8. Internal SRM vs water content before compaction and after compaction and $M_{r}$ test (Bandia limestone).

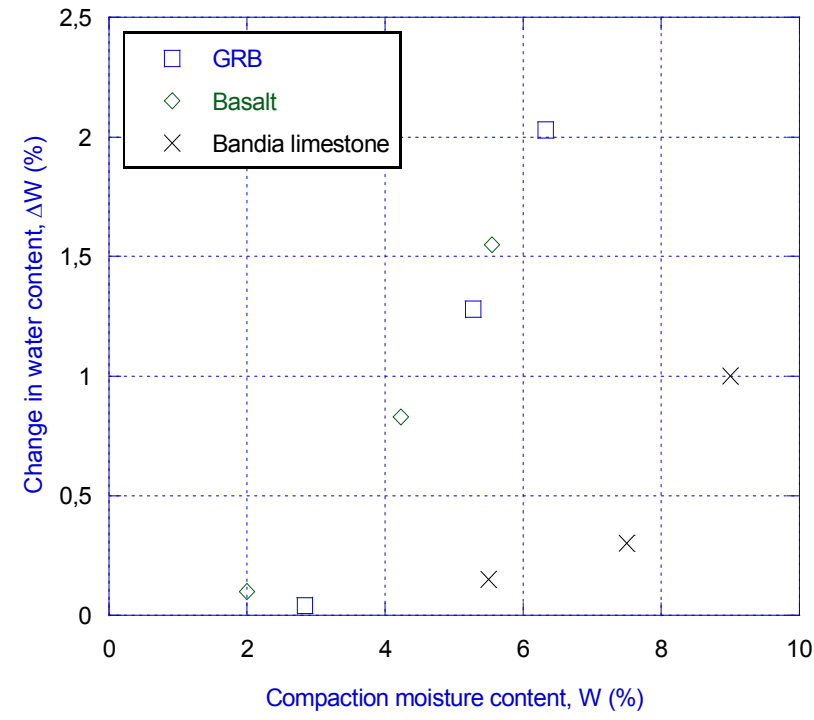

Figure 9. Change in Water content before and after $M_{r}$ test vs compaction moisture content.

\section{Conclusion}

Repeated triaxial load test was conducted on three different aggregates collected from different sites within Senegal (West Africa) in order to determine the effect of compaction moisture content on Resilient Moduli of unbound aggregates. Specimens were subjected to Resilient Modulus test in accordance with the NCHRP project 1-28A [12]. Test results show that the effect of water content is more significant in the dry side of the compaction curve than in the wet side. The compaction water content has less effect on the GRB and the Basalt than on the limestone. GRB and Basalt are cohesionless materials and allow water to drain even during the compaction procedure as shown by the change in water content of these materials before compaction and after compaction and Resilient Modulus test. Change in water content increases as the compaction water content increases because of the drainage of the excess water during the compaction procedure.

\section{Acknowledgements}

The authors would like to acknowledge the Geo-Engineering research group of the University of WisconsinMadison for their guidance and valuable input in this research project; and the "Entreprise Mapathé NDIOUCK" for supporting the high price shipping of aggregates from Senegal to Madison (USA).

\section{REFERENCES}

[1] E. J. Yoder and M. W. Witczak, "Principles of Pavement Design," 2nd Edition, Wiley, New York, 1975. doi:10.1002/9780470172919 
[2] T. C. Hopkins, T. L. Beckham and C. Sun, "Resilient Modulus of Compacted Crushed Stone Aggregate Bases," Research Report KTC-05-27/SPR-229-01-1F, Kentucky Transportation Center, College of Engineering, University of Kentucky, Lexington, 2007, p. 89.

[3] F. Lekarp, U. Isacsson and A. Dawson, "State of the Art. I: Resilient Response of Unbound Aggregates," Journal of Transportation Engineering, Vol. 126, No. 1, 2000.

[4] H. B. Seed, F. G. Mitry, C. L. Monismith and C. K. Chan, "Prediction of Flexible Pavement Deflections from Laboratory Repeated Load Tests," NCHRP Rep. No. 35, National Cooperative Highway Research Program, 1967.

[5] R. G. Hicks and C. L. Monismith, "Factors Influencing the Resilient Properties of Granular Materials," Highway Research Record, Vol. 345, 1971, pp. 15-31.

[6] M. Fall, A. Sawangsuriya, C. H. Benson, T. B. Edil and P. J. Bosscher, "On the Investigations of Resilient Modulus of Residual Tropical Gravel Lateritic Soils from Senegal (West Africa)," Geotechnical and Geological Engineering Journal, Vol. 26, No. 1, 2008, pp. 109-111.

[7] M. Ba, M. Fall, F. Samb, D. Sarr and M. Ndiaye, "Resilient Modulus of Unbound Aggregate Base Courses from Senegal (West Africa)," Open Journal of Civil Engineering, Vol. 1, No. 1, 2011, pp. 1-6. doi:10.4236/ojce.2011.11001

[8] ASTM C136-06, "Standard Test Method for Sieve Analysis of Fine and Coarse Aggregates," Annual Book of ASTM Standards, ASTM International, West Conshohocken, 2006.

[9] ASTM D1557-09, "Standard Test Methods for Laboratory Compaction Characteristics of Soil Using Modified Effort $\left(56,000 \mathrm{ft}-\mathrm{lbf} / \mathrm{ft}^{3}\left(2700 \mathrm{kN}-\mathrm{m} / \mathrm{m}^{3}\right)\right)$," Annual Book of ASTM Standards, ASTM International, West Conshohocken, 2009.

[10] ASTM C127-07, "Standard Test Method for Density, Relative Density (Specific Gravity), and Absorption of Coarse Aggregate," Annual Book of ASTM Standards, ASTM International, West Conshohocken, 2007.

[11] ASTM D6928-10, "Standard Test Method for Resistance of Coarse Aggregate to Degradation by Abrasion in the Micro-Deval Apparatus," Annual Book of ASTM Standards, ASTM International, West Conshohocken, 2010.

[12] NCHRP, "Laboratory Determination of Resilient Modulus for Flexible Pavement Design," National Cooperative Highway Research Program (NCHRP) Project 1-28A, Transportation Research Board of National Academies, 2004. 